IJMS 21 (1), 1-22 (2014)

\title{
WORK-LIFE BALANCE AND MANAGER PERFORMANCE IN BANGLADESH
}

\author{
A. K. M. MOMINUL HAQUE TALUKDER \\ MARGARET H. VICKERS \\ School of Business \\ University of Western Sydney
}

\begin{abstract}
The current interest in work-life balance (WLB) emanates from the perception that extreme workplace demands can have negative consequences for employees in other important life spheres such as family and leisure. Changes in society that increase the numbers of individuals with significant responsibilities both at home and at work have fuelled further inquiry into the interdependencies between work and home life. Much of the work-life research has been conducted in Western countries, so it is unknown whether theories, models and findings are valid in other settings despite the few studies from emerging economies such as Asia and Africa. The present study examined the effect of the determinants of WLB on individual performance in a developing country's context. Data were collected from a large logistic firm to identify the link between work environment, work pressure, discrimination, leave options, flexible work hours, employee benefits, and individual performance. Results revealed positive relationships of work environment, leave options, flexible work hours, and employee benefits with individual performance while it was negatively related to discrimination and work pressure. The findings suggested that a pragmatic work-life balance is required to have an increased level of performance. Theoretical and practical implications are discussed.
\end{abstract}

Keywords: Performance, work environment, work pressure, work-life balance.

\section{Introduction}

Work-life balance (WLB) has been defined as satisfaction and good functioning at work and at home, and with a minimum of role conflict (Clark, 2000). It has also been characterized elsewhere from another perspective as an absence of unacceptable levels of conflict between 
work and non-work demands (Greenblatt, 2002). But when demands from work and non-work domains overlap, conflict can occur; this lack of balance is commonly conceptualized as work/family conflict or work/non-work conflict (Frone, Yardley, \& Markel, 1997) and can occur either when work roles interfere with non-work roles, or vice versa. Time pressure is a serious problem for today's workers, with ever-increasing numbers of them bearing major responsibilities at home, and higher job expectations and heavier demands at work (Glass \& Finley, 2002; van der Lippe, 2007). This imbalance between family and work roles can be disadvantageous for both employees and employers. Past research has confirmed negative outcomes for workers and employers, including: higher stress levels and feelings of burnout; lower levels of job satisfaction, work performance, and organizational commitment; and more absenteeism due to workfamily conflict (Eby, Casper, Lockwood, Bordeaux, \& Brinley, 2005).

A few studies investigated the problem of work-life balance in workplaces in developing nations, such as Bangladesh. One such study (see Talukder, 2011) investigated the determinants of worklife balance affecting employee satisfaction in the service industry in Bangladesh. However, that study did not investigate the individual performance of workers in that organization, nor of managers in particular. The work presented here sheds light on the existing worklife balance literature, and is aimed at identifying the determinants of work-life balance that might be responsible for individual performance in a workplace in a developing nation. A better understanding of this would perhaps enable organizations, especially in developing nations, to facilitate more sustained performance outcomes from their employees. To craft effective solutions to work-life issues, it is paramount that researchers gather evidence of the scope and nature of the problems being faced, and consider such issues with an eye to relevant factors in the local cultural context. This is what this study aims to do.

\section{Literature Review}

Work and family are the two most important domains in a person's life and their interface has been the object of study for researchers worldwide for some years. There is a felt need by many workers to balance and integrate family needs and career requirements (Sturges 
\& Guest, 2004) and research in the field of work-family interface has increased dramatically in the past two decades (Frone et al., 1997). The changing social structures arising from dual-career couples, singleparent families, increasing numbers of parents with dependent-care responsibilities for children, and ageing parents, have all contributed to the need for increased research in the area of work-life balance.

Managers and professionals are not only working longer hours than previous generations, but are also experiencing a "sting of reality" when work demands increasingly spill into, and overshadow, family and personal life (MacInnes, 2005). WLB is an important area of human resource management which is receiving increased attention from policy-makers, employers, management, employees and their representatives, globally. In the US, research has increasingly recognized the phenomenon of "extreme jobs"-those characterized by gruelling working hours, unpredictable workflows, a fast workpace, tight deadlines, work-related events outside business hours, and 24/7 availability to clients (Hewlett \& Luce, 2006; Hochschild, 1997). And such significant workplace demands on employees are no longer restricted to Western nations.

\section{Bangladesh}

Since independence, over the past 43 years, Bangladesh has: increased its real per capita income by more than 130 per cent; cut poverty rates by 60 per cent; reduced total fertility rate from 7.0 to 2.7; increased life expectancy from 46.2 years to 66.6; increased the rate of economic growth from an average rate of 4 per cent in the 1970s to 6 per cent in the 2000s; and achieved gender parity in primary and secondary education (GOB, 2011). Notwithstanding this significant, recent progress, Bangladesh is still a low income country with substantial poverty, inequality and deprivation. An estimated 47 million people live below the poverty line with a significant proportion of these living in households which are female headed, in remote areas, and consisting of socially excluded and other vulnerable people. Most of the labour force is engaged in informal, low productivity, low income jobs. The poorest segment of the population is severely disadvantaged in terms of ownership of assets and has inadequate access to institutional finance as well as to basic services including quality education, healthcare, water and sanitation. 
There is a glaring under-representation of research from developing economies in the literature, especially research around work and family. Several authors have noted that studies into work-family programmes and work-life conflict have only been conducted in Western countries where such programmes are more widespread and research has been systematic, and generous. However, there remain relatively few studies from emerging economies such as Asia and Africa (Greenhaus \& Parasuraman, 1999; Poster \& Prasad, 2005).

This study focuses on WLB in the broader sense, and it is noted that other researchers have used a more specific focus on work-family balance (e.g. Lyness \& Kropf, 2005; Wierda-Boer, Gerris, \& Vermulst, 2008). Thus, it is noted that although "life" outside of work can include many life domains that may interact with one another, work and family remain, considered generally, to be the two most important domains in a person's life. The study of work-family balance (WFB) is also considered entirely relevant to the understanding of WLB. Organizations need to learn how they can encourage the highest levels of employees and organizational performance while simultaneously enabling employees to achieve a good balance between their work and family lives. The emerging WLB paradigm argues that employee work behaviour cannot be fully understood or explained by only considering organizational behaviour variables within the workplace setting (Brough \& Kalliath, 2009).

Recent advances in technology have enabled a more seamless interface between work and family. However, most of us would recognize the emotional fallout that can arise, even from positive workplaces, from the increasing encroachment of work on family life. Negative workplace experiences can impact spouses and other family members. Researchers have noted that relationships between workfamily conflict, job satisfaction and turnover intentions are stronger among workers employed within the Anglo countries (Australia, Canada, New Zealand, UK and the US) than for workers employed within Asia, Latin America and Eastern Europe (Spector et al., 2007), perhaps due to greater individualism in Western societies, where the response to adverse job conditions with dissatisfaction is often to leave the organization. People in more collectivistic societies, on the other hand, may be more likely to remain loyal to their employer and respond to workplace adversity via stronger affiliations with co-workers. When workers in individualistic societies display their 
dissatisfaction by leaving their employment, this is considered to be culturally acceptable. However, loyalty to an employer with a collectivist culture is a strong cultural norm, regardless of the individual worker's levels of dissatisfaction. Here, we will examine potential antecedents for work-life balance in a developing nation, such as Bangladesh and, especially, how those factors might influence the performance of managers in the service industry of Bangladesh.

\section{Work Environment}

Creating a positive workplace is critical to a company's success. Managers and supervisors can create positive workplaces for staff; to begin, they must define what a positive workplace might be by establishing good relationships, improving teamwork, and fostering innovations. The manager-staff relationship often has the greatest impact on performance (White, 2002) and it is important for managers to listen to and communicate sincerely with the staff, while providing positive reinforcement that is balanced, well-timed, and clear (White, 2002). Reinforcing positive actions, defining purpose, and setting clear goals are important to motivate staff (White, 2002) as is the existence of a mission statement that is perceived to be beneficial to both staff and customers (HRZone, 2000).

Managers can also have an impact on staff seeking a work-life balance. Managers who pursue a work-life balance in their own lives can offer a model of behaviour and welcome support to employees pursuing their own work-life balance by fostering an environment where a work-life balance is expected, enabled, and supported. Such managers may also find that they succeed in retaining outstanding employees to whom work-life balance is important. On this basis, it is hypothesized that:

H1: A positive workplace environment will be positively related to individual performance.

\section{Discrimination}

Discrimination in the workplace is one of the most distressing negative workplace behaviours that workers can encounter. Accordingly, considerable scholarly attention has been devoted to identifying the prevalence, causes, and consequences of workplace discrimination 
(Pager \& Shepherd, 2008). Feagin and Douglas (1980) conceptualized the major dimensions of discrimination as including: the motivation behind discriminatory actions; discriminatory actions; the effects of discriminatory actions; and, the context, both organizational and social, in which discrimination is embedded. Discrimination involves negative practices or actions undertaken at a place of work where a worker is treated differently because of his or her race, religion, sex, level of disability, or age, and perceptions of the existence of discrimination have been found to shape worker well-being (Kessler, Mickelson, \& Williams, 1999).

Examinations of work-to-life conflicts have been found to be better informed by considering perceptions of discrimination, rather than documented outcomes associated with perceived discrimination. Studies have found, for example, that perceived race discrimination is predictive of health-related work limitations, cardiovascular disease among men, depressive symptoms, perceived stress, lower self-esteem and lower grade point averages among African-American youth (Huynh \& Fuligni, 2010). Perceived sex discrimination has also been linked to negative worker outcomes, including psychological distress and decreased well-being (Foster, 2009) as has perceptions of age discrimination (Yuan, 2007). Therefore, it is hypothesized that:

H2: Discrimination is negatively related to individual performance.

\section{Work Pressure}

Work pressure also offers a source of conflict between personal and corporate life. Major, Klein and Ehrhart (2002) found that long working hours were associated with increased work-family conflict and, indirectly, with psychological distress, including increased depression and other stress related health problems. Furthermore, the more hours a week individuals worked, the more work interference into family life they reported. Wickens and Hollands (2000) confirmed that workload is inversely related to reserve capacity so long as capacity is not exceeded by task demands. However, when work demands exceed capacity (eliminating all reserve capacity) worker performance is bound to deteriorate. They also noted that the process of paying attention to several concurrent activities is itself demanding, beyond that of what is required to actually do 
the activities themselves. Also noted is the complex relationship between workload and stress (Gaillard, 2001). Stress is typically associated with excessively high workload levels, even being defined as part of the workload experience by some. However, it is noted that individuals who perceive their work performance as being successful, despite having high levels of perceived demands and associated high levels of effort expenditure, are still likely to experience considerable satisfaction at work, although perhaps concurrently with significant levels of stress. So, we cannot assume that high workloads are necessarily stressful, nor that people with high workloads are always dissatisfied with their jobs (Payne \& Morrison, 1999). People in such jobs might be dissatisfied for various reasons that may include high levels of stress or excessive workloads. However, they might also experience considerable satisfaction, engagement, enthusiasm and even exhilaration (Leiter, 1999). As such, it is hypothesized that:

H3: Work pressure is negatively related to individual performance.

\section{Leave Options}

Many employers offer employees various forms of paid leave, including vacations, paid time-off (PTO), and sick leave as part of their benefits package to allow employees to maintain or enhance wellbeing while responding to personal challenges. Many employers are required to grant employees job-protected leave under their national employment laws in Western nations, and also in Bangladesh.

When an organization in Bangladesh is recruiting and hoping to retain superior employees, employee leave and PTO policies can make a difference. PTO combines vacation, sick time and personal time into a single bank of days for employees to use to take paid time away from work. When an employee needs to take paid time away from work, the PTO policy enables employees, at their discretion, to use PTO to support their work-life balance. An employee may use the annual leave for vacations, rest and relaxation, as well as for personal business or to respond to emergencies. An employee in Bangladesh has the right to take annual leave, subject to the right of the supervisor to schedule the time when that annual leave might be taken, and they will then receive a lump-sum payment for accumulated and accrued annual leave. PTO plans have been found to reduce absenteeism in the workplace by helping employees balance work and home, and 
non-work pressures while helping employers control absentee costs. As a result, the popularity of PTO plans continues to grow (SHRM, 2009). Companies in Bangladesh can also implement a "use-it-or-loseit" policy to encourage employees to take time off when it is necessary, without adding an unnecessary burden of cost for that organization into the future. Therefore, it is hypothesized that:

H4: Having PTO leave options is positively related to individual performance.

\section{Employee Benefits}

An attractive employer-sponsored benefits programme also enables employers to retain and attract high quality employees. According to the Society for Human Resource Management (SHRM, 2009) Job Satisfaction Survey, employee benefits are one of the most important job satisfaction factors for employees and are important factors in retaining current and future staff. Thompson and Prottas (2006) found lower stress and reduced turnover intention when employees received social support from the organization. Introducing employment policies that encourage a healthier work-life balance for employees has been found to bring real benefits to businesses. Work-life balance policies can foster a more positive perception of the organization, leading to: improved employee relations; greater staff loyalty, commitment and motivation; reduced staff turnover; and, lower recruitment costs. The social exchange theory and the norm of reciprocity offer a theoretical basis for anticipating that work-life benefits would be positively reciprocated by employees in the form of positive attitudes and workplace behaviours (Lambert, 2000). Allowing employees to work flexibly in order to encourage a better work-life balance can also lead to improvements in health and wellbeing, with satisfaction around employee benefits also operating as a motivational factor among employees. As such, it is hypothesized that:

H5: Employee benefits are positively related to individual performance.

\section{Flexible Working Hours}

The availability of flexible work schedules are also recognized as enhancing job dedication (Muse, Harris, Giles, \& Feild, 2008) and organizational commitment (Grover \& Crooker, 1995). Research has found positive outcomes with certain types of workplace flexibility, 
but negative outcomes with others (Dalton \& Mesch, 1990; Stavrou, 2005). Employee-centered Flexible Working Arrangements (FWAs) are those that allow employees to work away from the office as well as offer flexibility in scheduling time at work. Employees prefer such arrangements in order to meet family, school or other nonwork responsibilities (Polivka \& Nardone, 1989). Flexible work arrangements are also thought to contribute to job motivation and dedication while enabling employees to use work-time more efficiently by scheduling activities in a way that suits their needs (Hill, Ferris, \& Martinson, 2003). Social and legislative frameworks, and national culture, in local workplace contexts may restrict or, conversely, encourage certain kinds of flexible work schedules. In some countries, legislative provisions promote flexible workplace arrangements; in others, such policy adoption is voluntary, and influenced by labour market conditions. Therefore, it is hypothesized that:

H6: Flexible work-hours are positively related to individual performance.

\section{Conceptual Model}

Over the past few decades, employer policies and practices to support work-life integration have proliferated as a means to attract and retain a high-quality workforce (Kossek \& Lambert, 2005). Work-life policies include any organizational programmes or officially sanctioned practices designed to assist employees with the integration of paid work with other important life roles such as family, education, or leisure. Examples of work-life policies include flexibility in the timing, location, or amount of work (e.g., flexitime, job sharing, parttime work, telework, leaves of absence), direct provision of caregiving and health benefits (e.g., child or elder care, domestic partner), and monetary and informational support for non-work roles (e.g., vouchers, referral services). A conceptual framework is a descriptive model of a system based on qualitative assumptions about its elements, their interrelationships, and system boundaries. This can guide research by providing visual representations of theoretical constructs (variables) of interest. In this study, individual performance is the dependent variable whereas leave options, employee benefits, work environment, flexible work hours, work pressure and discrimination are the independent variables as displayed in Figure 1. 


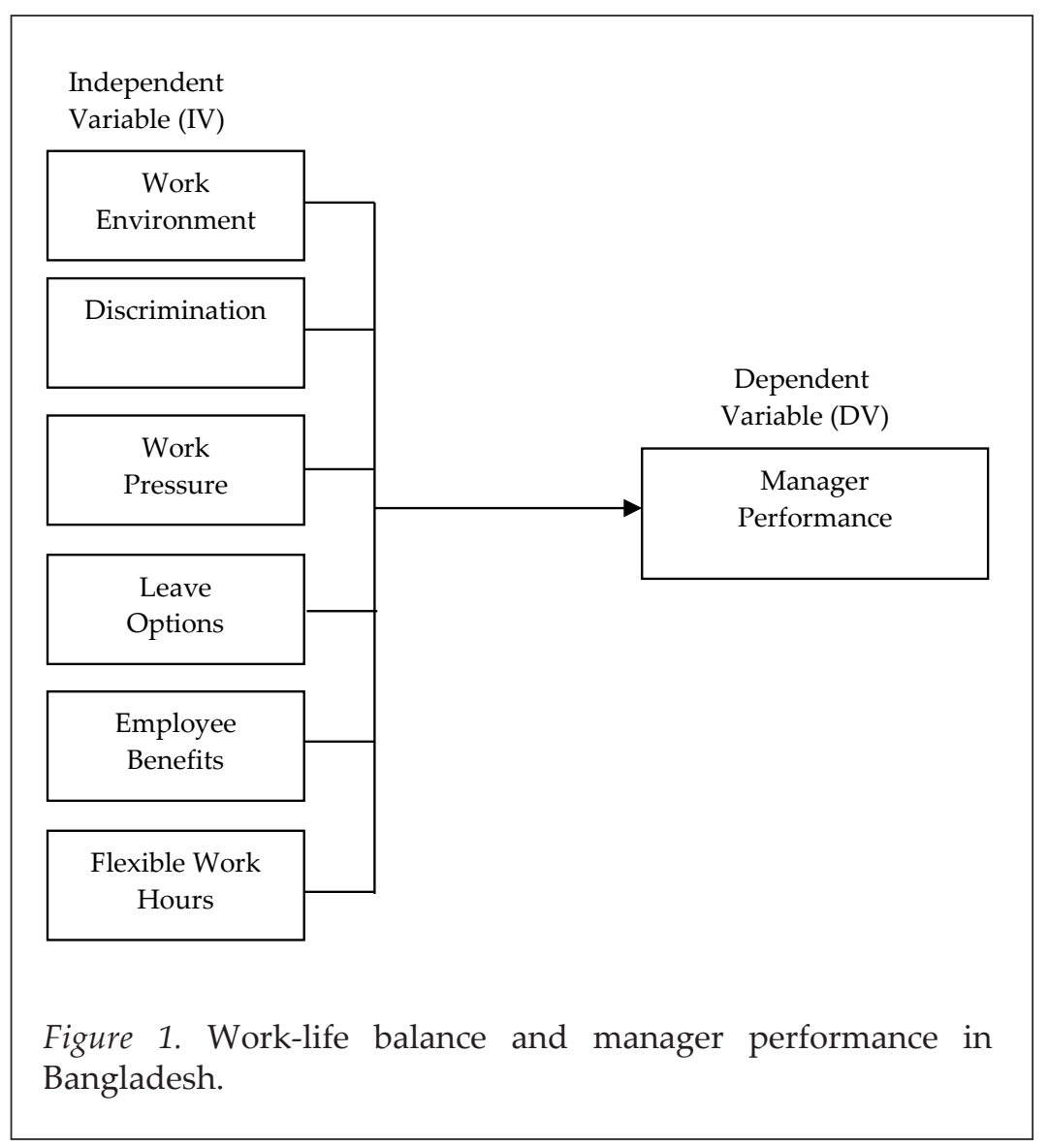

\section{Research Design}

\section{Participants}

Participants were full-time management employees of a leading logistic group operating in Dhaka, the capital of Bangladesh. Selection of a single industry and sector helped to control variances attributable to work sector differences (Hofstede, 2001). Managers were studied because they tend to work long hours and have high levels of responsibility and demands at work (Brett \& Stroh, 2003). It was also assumed that work-life issues needed to be perceived and initiated by managers, in order to have the most influence on the bottom-line of the organization. The organization's name has not been disclosed 
due to ethical obligations. A self-administered, structured survey questionnaire was used to gather data.

Questionnaires are routinely and extensively used for assessing organizational concerns, observing trends and evaluating progress, to good effect (Kraut, 1996). Respondent demographic information was also gathered, including gender, age, education, employment role, and level of experience. Of the total number of participants, 59 were male and 41 were female. Respondents' work levels included: top management (22 per cent), middle management (49 per cent), and frontline management staff ( 29 per cent). Their education levels included completion of: Master's degree (27 per cent), Bachelor's degree (58 per cent), and High School (15 per cent). Age range included: 20-29 years (42 per cent), 30-39 years (42 per cent), 40-49 years (12 per cent), and 50-59 years (4 per cent). Length of tenure ranged from: $0-5$ years' service (45 per cent), $6-10$ years ( 39 per cent), $11-15$ years (14 per cent), and, $16-20$ years ( 2 per cent).

\section{Sampling}

A hard copy of the survey was mailed to the respondents during March and April of 2011. The questionnaire was distributed to 245 staff at the nominated institution using convenience sampling. 74 questionnaires were returned to the researchers due to staff addresses being unknown, with 171 correctly mailed. Of these, 132 responses were received and, of these, 100 were complete and able to be used, giving an effective response rate of 40.81 per cent. Aaker, Kumar and Day (2001) suggest that a response rate for a mail survey without follow up of less than 20 per cent is acceptable. In Bangladesh, the effective response rate of mail surveys usually ranges between 40 per cent to 50 per cent. The response rate of this study was also consistent with an earlier study on workplace training in Bangladesh (Talukder \& Ahmed, 2012). A letter was attached to each questionnaire explaining the research and, deliberately, the survey contained no identifying participant information. Participants also received the questionnaires through the mail following ethical approval and were assured of confidentiality being maintained.

\section{Measurements}

The instrument comprised one dependent and six independent variables. The seven variables were measured using 35 questions, with each variable having 5 items. Rigorous literature review was used to 
support the validity of this self-administered questionnaire. Stevens (1996) confirmed that to frame an instrument and subsequently obtain data in a quantitative study there needs to be at least 20 respondents for each variable, which was present here and supports the statistical power to this research. Here, the effective sample size was 100 and consisted of six independent variables, and one dependent variable, with each having 5 items. The independent variables included: work environment, discrimination, leave options, employee benefits, work pressure, flexible work hours, and individual performance. All items used a 5-point Likert scale with responses ranging from highly disagree (1) to highly agree (5) and the items of each construct were in the form of statements that were direct, simple and concise. Participants ticked the boxes next to each question according to the extent of their agreement (scale was provided at the beginning of the questionnaire). SPSS software was used to analyse the data, including a reliability test, regression analyses and Pearson's correlations to investigate the relationships between the variables.

\section{Results}

Descriptive statistics, correlation coefficient and reliability values of all the constructs are displayed in Table 1 . The reliability value range was from 0.72 to 0.95 . This is consistent with George and Mallery's (2003) study, where the alpha value had to be greater than 0.7 to require further analysis. Mean scores were computed by equally weighting the mean scores of all the items. The mean value of work environment was 4.21 indicating very strong importance of the organizational work environment as an antecedent to performance. The mean value of discrimination was 2.11, which implied that workplace discrimination practices were a barrier to performance. The mean value of work pressure and leave options were 2.24 and 3.97 respectively; the former implying that if employees had moderate levels of work pressure it would contribute to their performance while the latter underscored that the leave options provided enhanced employees' performance. The mean values of employee benefits and flexible work hours were 4.05 and 3.70 respectively, signalling that employees perceived both benefits and flexible work hours to be helpful to their performance.

Hypothesis 1 predicted that a positive work environment would be positively related to individual performance. The study found (see Table 1) a significant positive relationship of the work environment with individual performance $\left(\mathrm{r}=0.80^{* *}, p<0.01\right)$. Hypothesis 2 
Table 1

Influences on Manager Performance in Bangladesh

\begin{tabular}{lccccccccc}
\hline Variables & Mean & SD & 1 & 2 & 3 & 4 & 5 & 6 & 7 \\
\hline 1. Work environment & 4.21 & .83 & .73 & & & & & & \\
2. Discrimination & 2.11 & .84 & -.00 & .78 & & & & & \\
3. Work pressure & 2.24 & .95 & .05 & $.63^{* *}$ & .85 & & & & \\
4. Leave options & 3.97 & 1.08 & $.50^{* *}$ & .03 & -.01 & .72 & & & \\
5. Employee benefits & 4.05 & 1.05 & $.49^{* *}$ & .09 & .05 & $.93^{* *}$ & .75 & & \\
6. Flexible working hours & 3.70 & 1.11 & $.21^{*}$ & -.07 & -.16 & $.53^{* *}$ & $.5^{* *}$ & .74 & \\
7. Individual performance & 4.26 & .75 & $.80^{* *}$ & -.05 & -.02 & $.50^{* *}$ & $.45^{* *}$ & $.22^{* *}$ & .95 \\
\hline
\end{tabular}

$N=100 ;{ }^{* *} p<.01 ;{ }^{*} p<.05 ;$ all items measured on 5-point scale.

predicted that discrimination would be negatively related to individual performance and the research confirmed a negative relationship between discrimination and individual performance. Hypothesis 3 predicted that work pressure would be negatively related to individual performance and the study confirmed that work pressure concurrently had negative and positive relationships with individual performance, depending on how much work pressure was experienced. Hypothesis 4 predicted that having leave options would be positively related to individual performance and the study found (See Table 1) a significant positive relationship between leave options and individual performance $\left(\mathrm{r}=0.50^{* *}, p<0.01\right)$. Hypothesis 5 predicted that employee benefits would be positively related to individual performance. The study found a significant positive relationship between the existence of employee benefits and individual performance $\left(\mathrm{r}=0.45^{* *}, p<0.01\right)$. Hypothesis 6 predicted that flexible working hours would be positively related to individual performance. The study also found a significant positive relationship between flexible working hours and individual performance.

To test the hypotheses, regression analysis was also conducted (See Table 2). The regression results supported Hypothesis 1 which stated a positive relationship between positive work environment and individual performance $(\beta=0.74, p<0.00)$. The regression results also showed a positive relationship between leave options and individual performance $(\beta=0.32, p<0.05)$. Moreover, both $\mathrm{F}$ value as well as Adjusted $R^{2}$ values exhibited significant relationships of all the variables with individual performance. All hypotheses were tested. 
IJMS 21 (1), 1-22 (2014)

Table 2

Regression Analysis of Factors Impacting Manager Performance

\begin{tabular}{|c|c|c|c|c|c|}
\hline \multirow[t]{2}{*}{ Variables } & \multicolumn{2}{|c|}{$\begin{array}{l}\text { Unstandardized } \\
\text { coefficients }\end{array}$} & \multicolumn{2}{|c|}{$\begin{array}{c}\text { Standardized } \\
\text { coefficients }\end{array}$} & \multirow[b]{2}{*}{ Sig } \\
\hline & B & $\begin{array}{l}\text { Std. } \\
\text { error }\end{array}$ & B & $\mathrm{T}$ & \\
\hline $\begin{array}{l}\text { Work } \\
\text { environment }\end{array}$ & .67 & .06 & .74 & 10.72 & .00 \\
\hline Discrimination & -.01 & .07 & -.01 & -.15 & .88 \\
\hline Work pressure & -.03 & .06 & -.03 & -.45 & .64 \\
\hline Leave option & .22 & .12 & .32 & 1.89 & .05 \\
\hline Employee benefit & .14 & .12 & .21 & 1.23 & .22 \\
\hline $\begin{array}{l}\text { Flexible working } \\
\text { hours }\end{array}$ & .01 & .04 & .01 & .19 & .85 \\
\hline $\mathrm{F}$ & 31.24 & & & & \\
\hline $\mathrm{R}$ & .82 & & & & \\
\hline $\mathrm{R}^{2}$ & .67 & & & & \\
\hline Adjusted $\mathrm{R}^{2}$ & .65 & & & & \\
\hline
\end{tabular}

Dependent: Individual performance.

\section{Discussion}

Different tests were undertaken to analyse and test the hypotheses. Hypothesis 1 was supported; it showed that a positive work environment in the organization had a significant positive relationship with individual performance. In other words, when a firm provides its employees with the necessary support, employees will perform better than those who are working in a less positive and supportive working environment, and vice versa. This finding confirms Schneider's (1987) claim, that "the people make the place." Vischer's (2007) study similarly incorporated psychological dimensions such as employee-employer relationships, motivation and advancement, job demands and social support as being key determinants of a positive work environment. A work environment that can provide a good balance of all these factors is said to be a favourable work environment. In contrast, a poor work environment is characterized 
by reduced job satisfaction, absenteeism, somatic complaints, burnout and depression (McCowan, 2001).

Hypothesis 2 was also supported by this research: A negative relationship was found between the presence of discrimination practices and individual performance. This is consistent with a past research. Loury (2002) and Steele (1997) found that perceived discrimination in the workplace may lead to diminished performance in education and the labour market, which can also give rise to further negative outcomes. Sanchez and Brock (1996) also examined the effects of perceived discrimination on work outcomes among 139 Hispanic male and female employees, and found that perceived discrimination contributed to increased work tensions, as well as decreased job satisfaction and organizational commitment, above and beyond other common work stressors, such as role conflict and ambiguity. Talukder (2011) also found a negative relationship between discrimination and job satisfaction in a service firm in Bangladesh. Gutek, Cohen, and Tsui (1996) also found that perceived discrimination among women was related to lower feelings of power and prestige on the job.

Hypothesis 3 was partially supported by the research. While the research found a negative relationship between high levels of work pressure and individual performance, lower levels of work pressure was seen to be positive for employee performance. Measuring high levels of working hours is a relatively objective indicator of work demands resulting in work pressure. Time is a limited commodity, and the number of hours spent at work leaves limited time available for family. As such, hours spent at work could be a precursor to timebased work interference with family (WIF). Too much time at work also takes people's energy and capability to meet family demands and, as such, working hours may also relate to greater strain-based WIF (Greenhaus \& Beutell, 1985). However, individuals who work the same number of hours may differ in their perception of the workload they face. People who perceive they have greater workloads are likely to feel that they have expended more effort than others while at work, which would then increase their strain-based WIF. Further, those with longer hours and perceived greater workloads may choose to spend more time at work to try and keep up, resulting in higher timebased WIF.

Hypothesis 4 was also supported, and showed that leave options had a significant positive relationship with individual performance. Proper leave policy ensures refreshment of employees and helps 
them to work more efficiently. It allows them to spend time with their families, socialize and do other things necessary to lead to both greater work-life balance and better job satisfaction. If provided with proper leave options, employees felt able to take a break from their otherwise busy work schedule allowing them to reduce their feelings of daily work pressure and enabling better performance.

Hypothesis 5 was also supported. Results confirmed that the perception of sufficient employee benefits has a significant positive relationship with individual performance. Different benefits satisfy and motivate mployees but past research confirms that employee benefits enhance employee satisfaction and that this, in turn, correlates positively with increased shareholder value. Arthur and Cooke (2004) also confirmed that work-family programmes that included employee benefits can engender greater commitment and stability among employees, thereby lowering the firm's costs and enhancing its profitability.

Finally, Hypothesis 6 was also supported and so confirms past research in this area. Grover and Crooker (1995) found that flexible work schedules are also associated with higher employee organizational commitment. Past evidence suggests that when greater autonomy is provided to employees via the use of flexible work schedules, this can result in positive outcomes for employees (Baltes, Briggs, Huff, Wright, \& Neuman, 1999; Saltzstein, Ting, \& Saltzstein, 2001), including perceptions of enhanced work/life balance professional employees (Baker, Avery, \& Crawford, 2007; Tausig \& Fenwick, 2001). Flexible work programmes offer employees more flexibility and control over their work schedules than more traditional working hours (Ronen, 1981).

\section{Conclusion}

The purpose of the study was to examine whether there was any relationship between the determinants of WLB (as previously suggested in the literature, might influence employees in the West) for employees working in a large logistic firm in Bangladesh. This has been achieved. However, more has been accomplished. Given the very limited research of WLB available in developing countries, especially with them being contrasted to Western societies, this study has shed some exploratory light on some of the likely determinants of WLB that will also influence the performance of employees, especially managers, in workplaces in Bangladesh. 
Six determinants were considered: Positive work environment, leave options, employee benefits, flexible working hours, work pressure, and workplace discrimination. These were investigated to find out their likely effect on individual performance in a workplace in Bangladesh. All the variables were found to have significantly moderated the individual performance of these employees. Furthermore, those with a positive relationships were found to significantly operate to elevate the performance level of the employees tested. The presence of workplace discrimination and high levels of work pressure were also found to have negative effects on individual performance, and were likely to undermine the job performance of employees if not responded to proactively. This study also surfaced cause and effect relationships between and among the variables and was observed in the correlation and regression analyses (see above).

The study did have some limitations. First the study was not generalizable as only one firm and one type of firm was represented, from a single industry. The sample size was also small $(n=100)$ and consisted exclusively of managers. Caution should be exercised before generalizing from these exploratory findings. The study was also limited to six independent variables and so ignored many other variables present in more traditional instruments. Also, the convenience sample made it difficult to generalize the findings. The data were also collected at a single point in time, meaning that no firm conclusions can be drawn regarding the causality of the relationships between WLB and employee performance. Further, data gathered was based on self-reporting, which has the potential to inflate correlations and limit the ability to make causal inferences. Indeed, the study did not examine all aspects of WLB, given the need to rely on a self-administered questionnaire. Further studies involving a mixed method might render different and more fulsome insights on WLB affecting performance of employees in the developing nation of Bangladesh. Also, a longitudinal study of WLB would enable cross-sectional and causal analyses in future. A more systematic investigation of the specific outcomes of WLB policies and strategies, at the individual, organizational and national levels is needed in Bangladesh.

To facilitate WFB for employees in workplaces in Bangladesh, these organizations are encouraged to introduce work-life policies to engage and support employees in a more productive manner. Such policies should include options designed to give workers greater flexibility in 
work scheduling (i.e., flexitime and telecommuting), to assist them with their parenting duties and other personal responsibilities (i.e., childcare). The presence of such policies will also offer emotional support to all employees, via more supportive leadership and a more positive organizational culture. Previous studies confirm that organizational support increases organizational commitment and motivates employees to expend more effort in their work.

Family life should be a source of personal fulfillment, and self-respect, and effort should be invested in workplaces to assist in this area to assist employees' ability to fulfill their domestic duties. Moreover, engagement in family life can help employees develop skills, and gain experience and knowledge that they can also use at work. Participating in both family life and work extends an employee's network and thus, his or her social capital. Over the past few decades, employer policies and practices to support work-life integration have proliferated as a means to attract and retain a high-quality workforce in Western countries. It is time for developing nations to consciously follow this path.

\section{References}

Aaker, D. A., Kumar, V., \& Day, G. S. (2001). Marketing research. New York: John Wiley and Sons.

Arthur, M. M., \& Cooke, A. (2004). Taking stock of work-family initiatives: How announcements of family-friendly' human resource decisions affect shareholder value? Industrial and Labor Relations Review, 57(4), 599-613.

Baker, E., Avery, G. C., \& Crawford, J. (2007). Satisfaction and perceived productivity when professionals work from home. Research and Practice in Human Resource Management, 15(1), 37-62.

Baltes, B., Briggs, T. E., Huff, J. W., Wright, J. A., \& Neuman, G. A. (1999). Flexible and compressed workweek schedules: A metaanalysis of their effects on work-related criteria. Journal of Applied Psychology, 84(4), 496-513.

Brett, J., \& Stroh, L. (2003). Working 61-plus hours a week: Why do managers do it? Journal of Applied Psychology, 88, 67-78.

Brough, P., \& Kalliath, T. (2009). Work-family balance: Theoretical and empirical advancements. Journal of Organizational Behavior, 30(5), 581-585.

Clark, S. (2000). Work-family border theory: A new theory of worklife balance. Human Relations, 53(6), 747-770. 
Dalton, D. R., \& Mesch, D. J. (1990). The impact of flexible scheduling on employee attendance and turnover. Administrative Science Quarterly, 35(2), 370-387.

Eby, L. T., Casper, W. J., Lockwood, A., Bordeaux, C., \& Brinley, A. (2005). Work and family research in IO/OB: Content analysis and review of the literature (1980-2002). Journal of Vocational Behavior, 66(1), 124-197.

Feagin, J. R., \& Douglas, L. E. (1980). Discrimination: Motivation, action, effects, and context. Annual Review of Sociology, 6(1), $1-20$.

Foster, M. (2009). The dynamic nature of coping with gender discrimination: Appraisals, strategies, and well-being over time. Sex Roles, 60(9/10), 694-707.

Frone, M. R., Yardley, J. K., \& Markel, K. S. (1997). Developing and testing an integrative model of the work-family interface. Journal of Vocational Behavior, 50, 145-167.

Gaillard, A. W. K. (2001). Stress, workload, and fatigue as three bio behavioral states: A general overview. In P. A. Hancock \& P. A. Desmond (Eds.), Stress, workload, and fatigue (pp. 623-639). New Jersey: Lawrence Erlbaum.

George, D., \& Mallery, P. (2003). SPSS for Windows step by step: A simple guide and reference. 11.0 update. Boston: Allyn \& Bacon.

Glass, J. L., \& Finley, A. (2002). Coverage and effectiveness of familyresponsive workplace policies. Human Resource Management Review, 12(3), 313-337.

Government of Bangladesh, GOB. (2011). Strategic directions and policy framework, planning commission. Ministry of Planning. People's Republic of Bangladesh.

Greenblatt, E. (2002). Work-life balance: Wisdom or whining Organizational Dynamics, 31(2), 177-193.

Greenhaus, J. H., \& Beutell, N. J. (1985). Sources of conflict between work and non-work family roles. Academy of Management Review, 10, 76-85.

Greenhaus, J. H., \& Parasuraman, S. (1999). Research on work, family, and gender. In G. Powell (Ed.), Handbook of gender \& work (pp. 391-412). California: Sage Publications.

Grover, S. L., \& Crooker, K. J. (1995). Who appreciates familyresponsive human resource policies: The impact of familyfriendly policies on the organizational attachment of parents and non-parents? Personnel Psychology, 48(2), 271-288.

Gutek, B. A., Cohen, A. G., \& Tsui, A. (1996). Reactions to perceived discrimination. Human Relations, 49(6), 791-813.

Hill, E. J., Ferris, M., \& Martinson, V. (2003). Does it matter where you work? A comparison of how three work venues influence 
aspects of work and personal/family life. Journal of Vocational Behavior, 63(2), 220-241.

Hewlett, S. A., \& Luce, C. B. (2006). Extreme jobs: The dangerous allure of the 70-hour work week. Harvard Business Review, 12, 49-59.

Hochschild, A. R. (1997). The time bind. New York: Holt.

Hofstede, G. (2001). Culture's consequences, second edition: Comparing values, behaviours, institutions and organizations across nations. Thousand Oaks CA: Sage Publications.

HRZone. (2000). Associate recognition and motivation. Academic Emporia. Retrieved from http: //www.academic.emporia.edu

Huynh, V. W., \& Fuligni, A, J. (2010). Discrimination hurts: The academic, psychological, and physical well-being of adolescents. Journal of Research on Adolescence, 20(4), 916-941.

Kessler, R. C., Mickelson, K. D., \& Williams, D. R. (1999). The prevalence, distribution, and mental health correlates of perceived discrimination in the United States. Journal of Health and Social Behavior, 40(3), 208-230.

Kossek, E. E., \& Lambert, S. J. (2005). Work and life integration: Organizational, cultural and individual perspectives. Mahwah, NJ: Erlbaum.

Kraut, A. I. (1996). Organizational surveys: Tools for assessment and change. San Francisco, CA: Jossey-Bass.

Lambert, S. (2000). Added benefits: The link between work-life benefits and organizational citizenship. Academy of Management Journal, 43(5), 801-815.

Leiter, M. (1999). The impact on staff members of a hospital merger in Dublin. Paper presented to APA-NIOSH Conference on Work, Stress, and Health '99: Organization of Work in a Global Economy, Baltimore. Washington DC: American Psychological Association.

Loury, G. C. (2002). The anatomy of racial inequality. Cambridge, MA: Harvard University Press.

Lyness, K. S., \& Kropf, M. B. (2005). The relationships of national gender equality and organizational support with work-family balance: A study of European managers. Human Relations, 58, 33-60.

MacInnes, J. (2005). Work-life balance and demand for reduction in working hours: Evidence from the British Social Attitudes Survey 2002. British Journal of Industrial Relations, 43(2), 273-295.

Major, V. S., Klein, K. J., \& Ehrhart, M. G. (2002). Work time, work interference with family, and psychological distress. Journal of Applied Psychology, 87(3), 427-436. 
McCowan, B. (2001). Self-reported stress and its effects on nurses. Nurs Standard, 42, 33-38.

Muse, L., Harris, S. G., Giles, W. F., \& Feild, H. S. (2008). Worklife benefits and positive organizational behavior: Is there a connection? Journal of Organizational Behavior, 29(2), 171-192.

Pager, D., \& Shepherd, H. (2008). The sociology of discrimination: Racial discrimination in employment, housing, credit, and consumer markets. Annual Review of Sociology, 34, 181-209.

Payne, R. L., \& Morrison, D. (1999). The importance of knowing the affective meaning of job demands revisited. Work and Stress, 13(3), 280-288.

Polivka, A. E., \& Nardone, T. (1989). On the definition of 'contingent work'. Monthly Labor Review, 12(12), 9-17.

Poster, W. R., \& Prasad, S. (2005). Work-family relations in transnational perspective: A view from high-tech firms in India and the United States. Social Problems, 52(1), 122-146.

Ronen, S. (1981). Flexible work hours: An innovation in the quality of work life. New York: McGraw-Hill.

Saltzstein, A. L., Ting, Y., \& Saltzstein, G. (2001). Work-family balance and job satisfaction: The impact of family-friendly policies on attitudes of government employees. Public Administrative Review, 61(4), 452-467.

Sanchez, J. I., \& Brock, P. (1996). Outcomes of perceived discrimination among Hispanic employees: Is diversity management a luxury or a necessity? Academy of Management Journal, 39, 704-719.

Schneider, B. (1987). The people make the place. Personnel Psychology, 40(3), 437-454.

Society for Human Resource Management (SHRM). (2009). Examining paid leave in the workplace: Helping your organization attract and retain talented employees. A survey report.

Spector, P. E., Allen, T. D., Poelmans., S. Lapierre., L. M., Cooper, C. L., \& O'Driscoll., M. (2007). Cross-national differences in relationships of work demands, job satisfaction and turnover intentions with work-family conflict. Personnel Psychology, 60(4), 805-835.

Stavrou, E. (2005). Flexible work bundles and organizational competitiveness: A cross-national study of the European work context. Journal of Organizational Behavior, 26(8), 923-947.

Steele, C. A. (1997). Threat in the air: How stereotypes shape intellectual identity and performance. American, 52(6), 613-629.

Stevens, J. (1996). Applied multivariate statistics for social sciences. Mahwah, NJ: Lawrence Erlbaum. 
Sturges, J., \& Guest, D. (2004). Working to live or living to work? Work/ life balance early in the career. Human Resource Management Journal, 14(4), 5-20.

Talukder, AKMMH. (2011). A shifting paradigm of work-life balance in service industry: An empirical study. Indus Journal of Management \& Social Science, 5(1), 10-23.

Talukder, AKMMH, \& Ahmed J. U. (2012). Effect of strategic determinants of training on the job performance and efficiency and effectiveness: An empirical investigation. Malaysian Management Journal, 16, 23-42.

Tausig, M., \& Fenwick, R. (2001). Unbinding time: Alternate work schedules and work-life balance. Journal of Family and Economic Issues, 22(2), 101-119.

Thompson, C. A., \& Prottas, D. J. (2006). Relationships among organizational family support, job autonomy, perceived control, and employee well-being. Journal of Occupational Health Psychology, 10(4), 100-118.

van der Lippe, T. (2007). Dutch workers and time pressure: Household and workplace characteristics. Work, Employment and Society, 21(4), 693-711.

Vischer, J. C. (2007). The effects of the physical environment on job performance: Towards a theoretical model of workspace stress. Stress and Health, 23, 175-184.

White, T. (2002). The human element. One more time: Tell me about motivation. Retrieved from http://www.thefabrocator.com

Wickens, C. D., \& Hollands, J. G. (2000). Engineering psychology and human performance. New Jersey: Prentice Hall.

Wierda-Boer, H. H., Gerris, J. R. M., \& Vermulst, A. A. (2008). Adaptive strategies, gender work and family role commitments. Counseling Psychology Quarterly, 20, 267-285.

Yuan, A. S. V. (2007). Perceived age discrimination and mental health. Social Forces, 86(1), 291-311. 